\title{
Inhibition of proliferation of human lung cancer cells by green tea catechins is mediated by upregulation of let-7
}

\author{
ZHIWEI ZHONG ${ }^{1}$, ZHUO DONG ${ }^{1}$, LIHUA YANG ${ }^{1}$, XIAOQIANG CHEN ${ }^{2}$ and ZHAOHUI GONG ${ }^{1}$ \\ ${ }^{1}$ Institute of Biochemistry and Molecular Biology, School of Medicine, Ningbo University, Ningbo 315211; \\ ${ }^{2}$ Hangzhou Tea Research Institute, All China Federation of Supply and \\ Marketing Cooperatives, Hangzhou 310016, P.R. China
}

Received February 24, 2012; Accepted May 8, 2012

DOI: $10.3892 / \mathrm{etm} .2012 .580$

\begin{abstract}
Green tea catechins are known to function as anticancer agents via inhibition of carcinogenesis during the initiation, promotion and progression stages. Many potential mechanisms have been proposed, yet the precise mechanism of lung cancer prevention by green tea catechins remains unclear. microRNAs (miRs) are a class of 21-24 nucleotide small non-coding RNAs and play critical roles throughout cellular development and regulation. Emerging evidence demonstrates that tea catechins influence the expression of miRs in human cancer cells to inhibit tumorigenesis. Both let-7a-1 and let- $7 \mathrm{~g}$ were detected in the human lung cancer cells treated with tea catechins. The cell viability and cell cycle were analyzed after tea catechins treatment. In the present study, we found that tea catechins upregulated the tumor-suppressor miRs, let-7a-1 and let-7g, in lung cancer cell lines. The upregulation of let- $7 \mathrm{a} / 7 \mathrm{~g}$ repressed the expression of their targets, C-MYC and the regulatory protein of $\mathrm{LIN}-28$, at the $\mathrm{mRNA}$ and protein levels. Moreover, the cell growth assay indicated that tea catechins significantly inhibited cell proliferation, and the flow cytometric analysis revealed an increase in the number of cells in the $\mathrm{G} 2 / \mathrm{M}$ phase and a decrease in the number of cells in the $\mathrm{S}$ phase after treatment with tea catechins. These observations suggest that green tea catechins mediate the inhibition of proliferation of lung cancer cells through the let-7 signaling pathway.
\end{abstract}

\section{Introduction}

Lung cancer is one of the most common malignant tumors and the leading cause of cancer-related mortality worldwide (1). Small-cell lung carcinoma (SCLC) is the most aggressive

Correspondence to: Professor Zhaohui Gong, Institute of Biochemistry and Molecular Biology, School of Medicine, Ningbo University, 818 Fenghua Road, Ningbo 315211, P.R. China

E-mail: zhaohui@ncri.org.cn

Key words: anticancer, let-7, LIN-28, C-MYC, microRNA, tea catechin subtype of all lung tumors and is associated with poor patient survival (2). Although the investigation of known genes and proteins has yielded much new information, previously unknown biomarkers such as non-coding RNA gene products may also lend insight into the biology of lung cancer. Further investigation of the use of differential microRNA (miR) expression in the diagnosis, prognosis and treatment of lung cancer is warranted.

miRs are a class of short, single-stranded, endogenous and highly conserved non-coding RNAs that are involved in numerous developmental processes and the modulation of gene expression. Recent studies have demonstrated that various miRs, such as let-7, miR-15 and miR-16, are downregulated in human cancer cells and may function as tumor suppressors (3-6). Conversely, various miRs, including miR-21, miR-31 and miR-155, are upregulated in human cancer cells and may function as oncomirs (oncogene miRs) (7-9). Members of the let-7 family of miRs are expressed at an extremely low level in lung cancer (10) and act as tumor suppressors by repressing cell proliferation and regulating multiple oncogenes, such as $R A S$ and $C-M Y C$ (11-14). In addition, the $C-M Y C$ oncogene was found to regulate the expression of the pluripotency factor LIN-28, which modulates the process of mature let-7 (15). Therefore, the upregulation of let-7 expression may inhibit cell proliferation by downregulating the $C-M Y C$ and $L I N-28$ expression signaling pathway in lung cancer cells.

Tea, one of the most popular beverages consumed worldwide, has received much attention due to its disease prevention effects $(16,17)$. Studies have shown that these effects are attributed to the polyphenolic constituents which are present in high amounts in green tea (18). The inhibitory effects of tea catechins against experimental carcinogenesis have also been demonstrated in many animal models (19-21). In recent years, it has been reported that tea catechins induce the modification of the expression profile of miRs and mediate the apoptotic effect in human cancer cells $(22,23)$. Furthermore, let-7 is known as a tumor suppressor in lung cancer cells or animal models by repressing cell proliferation (10,24-26) and its expression profile may be altered by various agents $(23,27,28)$. However, the effect and mechanism of tea catechins on let-7 expression in human lung cancer remain unknown. Here, we identified let-7a-1, let-7g, C-MYC and $L I N-28$ expression levels in human lung cancer cells after tea catechin treatment and 
Table I. Primer sequences for real-time RT-PCR.

\begin{tabular}{lll}
\hline Genes & Forward primer sequences $\left(5^{\prime} \rightarrow 3^{\prime}\right)$ & \multicolumn{1}{c}{ Reverse primer sequences $\left(5^{\prime} \rightarrow 3^{\prime}\right)$} \\
\hline$l e t-7 a-1$ & CGATTCAGTGAGGTAGTAGGTTGT & TATGGTTGTTCTGCTCTCTGTCTC \\
$l e t-7 g$ & CGCCAGTTGAGGTAGTAGTTTGTA & TATGGTTGTTCTGCTCTCTGTCTC \\
$U 6$ sn $R N A$ & CTCGGTTCGGCAGCACA & AACGCTTCACGAATTTGCGT \\
$C-M Y C$ & CCACCAGCAGCGACTCTGA & GCAGAAGGTGATCCAGACTC \\
$L I N-28$ & AGGCGGTGGAGTTCACCTTTAAGA & AGCTTGCATTCCTTGGCATGATGG \\
$\beta$ - $a$ t $t$ in & CAGAAGGAGATTACTGCTCTGGCT & TACTCCTGCTTGCTGATCCACATC \\
\hline
\end{tabular}

found that tea catechins repressed cell proliferation of lung cancer cells through upregulation of let-7 and downregulation of the $C-M Y C, L I N-28$ signaling pathway.

\section{Materials and methods}

Cell lines and tea catechins. NCI-H446 and MSTO-211H lung cancer cells were purchased from the Cell Resource Centre of the Shanghai Institutes for Biological Sciences of the Chinese Academy of Sciences (Shanghai, China) and cultured in RPMI-1640 medium (Invitrogen Life Technologies, Carlsbad, CA, USA) containing 10\% fetal bovine serum (Hyclone, USA). These two cell lines overexpress the C-MYC protooncogene. The tea catechins were extracted from green tea by the All China Federation of Supply and Marketing Cooperatives (ACFSMC) (Hangzhou, China) and the purity was $85 \%$. The catechins were dissolved in double-distilled $\mathrm{H}_{2} \mathrm{O}$ and stored at $-20^{\circ} \mathrm{C}$ for research use.

Tea catechin stimulation. Prior to tea-catechin treatment, the cells were maintained in a humidified incubator at $37^{\circ} \mathrm{C}$ in $5 \% \mathrm{CO}_{2}$ and the media were replaced two times/week. Logarithmically growing lung cancer cells were harvested

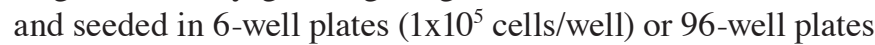
$\left(1 \times 10^{4}\right.$ cells/well). After overnight proliferation, the adherent cells were incubated with tea catechins at final concentrations of $0,50,100$ and $200 \mu \mathrm{g} / \mathrm{ml}$ for $24-96 \mathrm{~h}$. At the end of each treatment, the cells were used for cell growth assay.

Quantitative real-time RT-PCR for miRs and relative gene expression. Forty-eight hours post-treatment, total-RNA was isolated from the cells using RNAiso reagent (Takara Bio, Inc., Shiga, Japan) according to the manufacturer's instructions. One microgram of total-RNA was subjected to reverse transcription reaction. Quantitative real-time RT-PCR of miRs (let-7a-1/7g) was performed using the Hairpin-it ${ }^{\mathrm{TM}}$ miR qPCR quantitation kit (Shanghai GenePharma, Co., Ltd., Shanghai, China) and the SYBR-Green PCR master mix (Takara Bio, Inc.) in the Mx3005P real-time PCR system (Stratagene, USA) for quantitative miR detection. The reactions were performed in 8-strip tubes (Axygen, USA) at $95^{\circ} \mathrm{C}$ for $2 \mathrm{~min}$, followed by 40 cycles of $95^{\circ} \mathrm{C}$ for $15 \mathrm{sec}$ and $62^{\circ} \mathrm{C}$ for $1 \mathrm{~min}$. Data were analyzed by MxPro 3.2 according to the manufacturer's instructions. The analysis of miR-related genes $(C-M Y C$ and $L I N-28)$ was carried out by quantitative real-time RT-PCR. The reactions were performed at $95^{\circ} \mathrm{C}$ for $2 \mathrm{~min}$, followed by 40 cycles of $95^{\circ} \mathrm{C}$ for $20 \mathrm{sec}$ and $60^{\circ} \mathrm{C}$ for $1 \mathrm{~min}$ and $\beta$-actin was used as an internal control. The primer sequences for qPCR and RT-PCR are shown in Table I.

Cell viability assay. At 24, 48, 72 and 96 h post-treatment using different concentrations of tea catechins, $20 \mu \mathrm{l}$ of 3-(4,5-dimethylthiazol-2-yl)-2,5-diphenyltetrazolium bromide (MTT, $5 \mathrm{mg} / \mathrm{ml}$ ) was added to each well, and the cells were incubated for $4 \mathrm{~h}$ at $37^{\circ} \mathrm{C}$ in $5 \% \mathrm{CO}_{2}$. After incubation, the medium was carefully removed from the plates, and $150 \mu \mathrm{l}$ of dimethyl sulfoxide (DMSO) was added to solubilize the formazan produced from MTT by the viable cells. Absorbance was measured at $490 \mathrm{~nm}$ by using an automatic microplate reader (Labsystems, Helsinki, Finland).

Flow cytometry. Twenty-four hours post-stimulation by tea catechins, the cells were harvested and washed with cold PBS and then fixed in $70 \%$ ice-cold ethanol for $24 \mathrm{~h}$. After washing with PBS, the cells were incubated with $1 \mu \mathrm{g} / \mathrm{ml}$ propidium iodide (PI) for $30 \mathrm{~min}$ at room temperature before FACS Calibur system (Becton-Dickinson, USA) analysis. The data were collected and processed using the ModFit LT FACS analysis software.

Western blot analysis. Forty-eight hours after tea catechin treatment, the cells were washed three times with cold PBS and lysed in ice-cold lysis buffer (50 mM Tris-HCl, $\mathrm{pH} 8.0,150 \mathrm{mM}$ $\mathrm{NaCl}, 1 \%$ Triton X-100, $100 \mu \mathrm{g} / \mathrm{ml}$ PMSF). Thirty minutes later, the cell pellets were collected by scraping. They were then transferred to new tubes and centrifuged at $12,000 \mathrm{rpm}$ for $15 \mathrm{~min}$ at $4^{\circ} \mathrm{C}$. The supernatant was used for protein quantitative analysis by the Bradford procedure (Bio-Rad, USA) and then for western blot analysis. The proteins were resolved on $12 \%$ SDS-polyacrylamide gels, transferred onto PVDF membranes and incubated with appropriate antibodies according to the manufacturer's instructions. The rabbit polyclonal antibody of anti- $\beta$-actin (Beijing Bioss Biotechnology, Beijing, China) was used at a 1:500 dilution, the rabbit monoclonal anti-LIN-28 antibody (Epitomics, Inc., USA) was used at a 1:5,000 dilution, and the secondary antibody of IgG-HRP (Sigma, USA) was used at a 1:6,000 dilution. Color development reaction of HRP was performed using the BeyoECL Plus system (Beyotime, Haimen, China). The Quantity One analysis program (Bio-Rad) was used to obtain the quantitative data.

Statistical analysis. The experimental data are expressed as the mean $\pm \mathrm{SD}$ of three independent experiments, and all experiments were performed in triplicate. The statistical significance between different groups was determined using a 

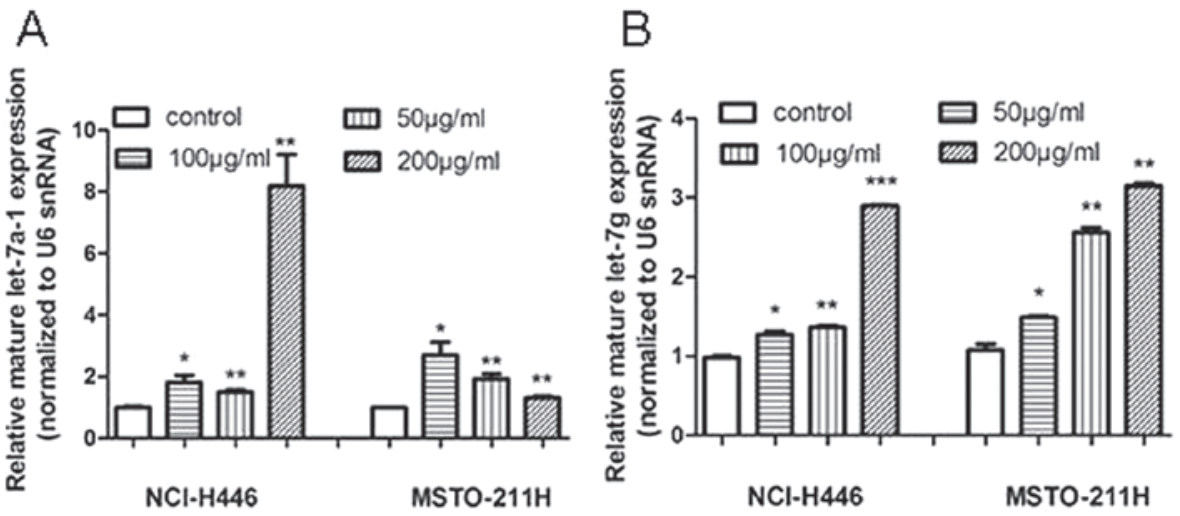

Figure 1. Tea catechins upregulated (A) let-7a-1 and (B) let-7g expression in NCI-H446 and MSTO-211H cells. U6 snRNA was used as an internal control. "P $<0.05,{ }^{* * *} \mathrm{P}<0.01$ and ${ }^{* * * *} \mathrm{P}<0.001$ compared to the control.

A

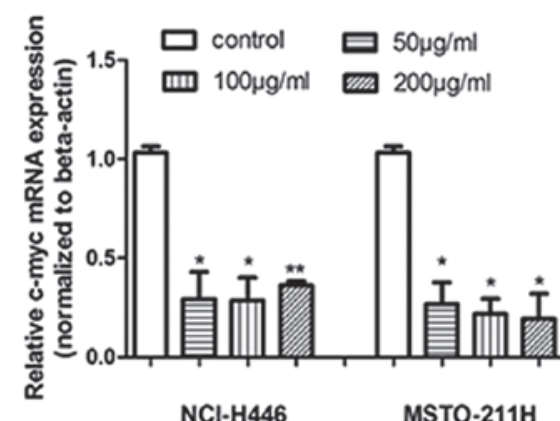

C
B

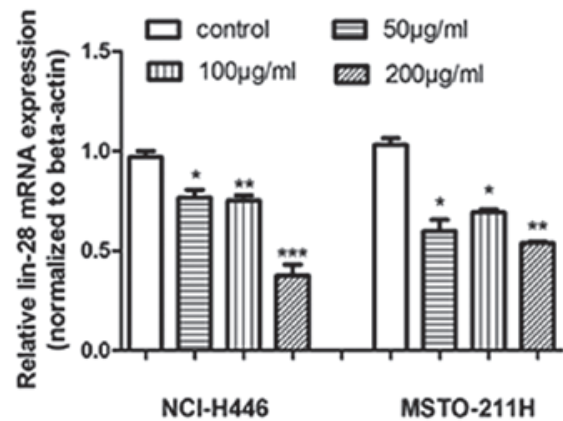

D

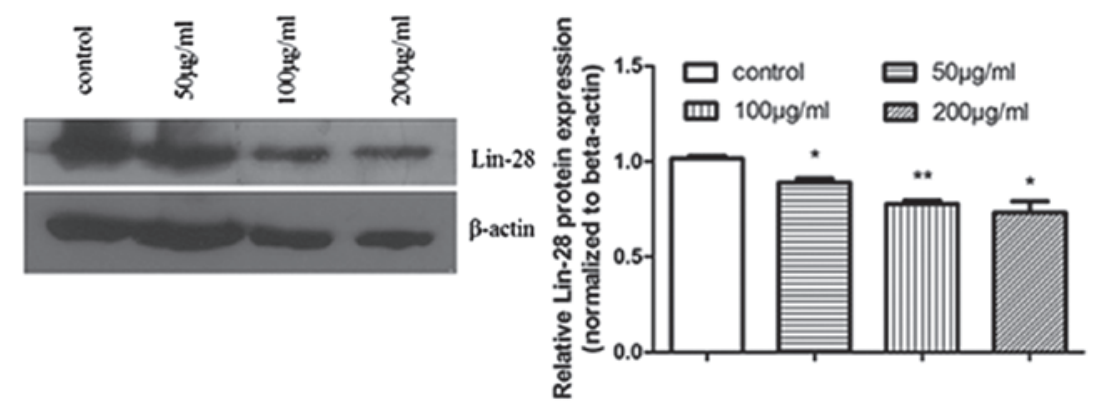

Figure 2. Effects of tea catechins on let-7a-1/7g targeted gene expression: (A) C-MYC mRNA level; (B) LIN-28 mRNA level; (C) LIN-28 protein level (D) Quantitative analysis of LIN-28 protein by the Quantity One program. ${ }^{*} \mathrm{P}<0.05,{ }^{* *} \mathrm{P}<0.01$ and ${ }^{* * *} \mathrm{P}<0.001$ compared to the control.

two-tailed Student's t-test. A P-value of $<0.05$ was considered to indicate a statitically significant difference.

\section{Results}

let-7 expression is upregulated after tea catechin treatment. To determine whether let-7a-1 and let-7g are involved in the response of lung cancer cells to tea catechin treatment, NCI-H446 and MSTO-211H cells were incubated with different doses of tea catechins before miR analysis. The qRT-PCR results of miRs showed that both of the mature let-7a-1 and let-7g were upregulated from the dose of $50 \mu \mathrm{g} / \mathrm{ml}$, and their induced expression levels were markedly higher than those of the control groups (Fig. 1A and B). Moreover, tea catechins upregulated let-7g in a dose-dependent manner in both cell lines (Fig. 1B). Taken together, these results demonstrated that tea catechins upregulated the expression of the tumor-suppressor miRs, let-7a-1 and let-7g.

Tea catechins repress let- 7 target and regulatory gene expression. For further confirmation of the effect of tea catechins on let-7 target and regulatory gene expression, we used qRT-PCR to detect the let-7 target gene $C-M Y C$ and its regulatory gene $L I N-28$, at the mRNA level. C-MYC and LIN-28 mRNA expression was significantly reduced $48 \mathrm{~h}$ after treatment of the NCI-H446 and MSTO-211H cells with tea catechins (Fig. 2A and B). To identify the effect of tea catechins on the expression of let-7 regulatory protein LIN-28, we further detected 
A
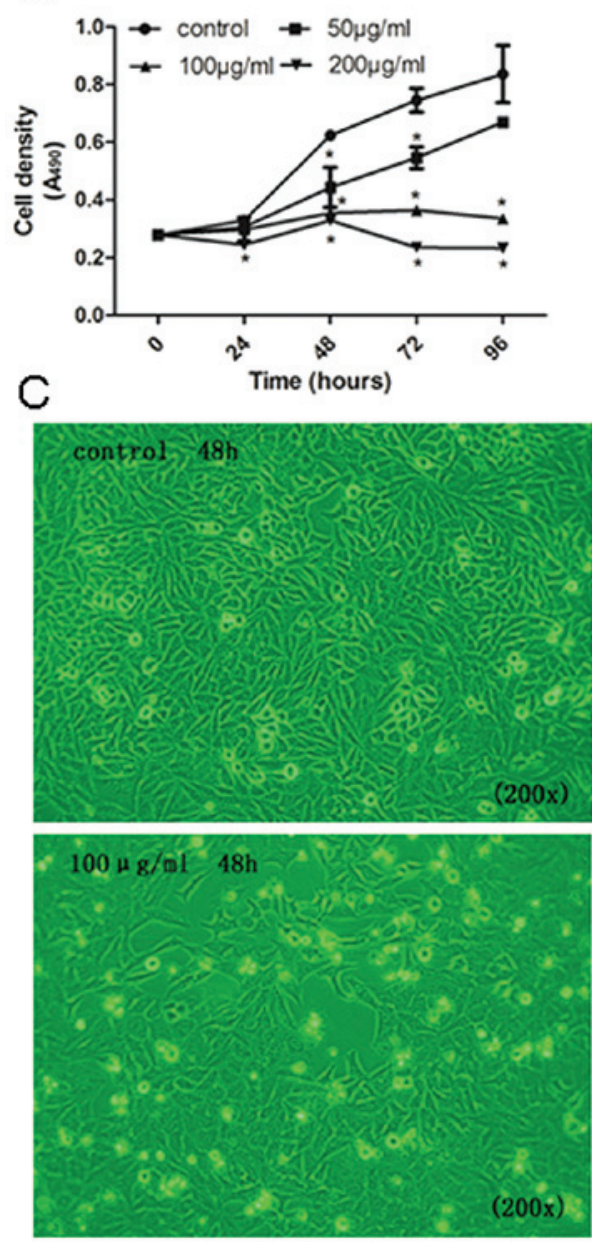

$\mathrm{B}$
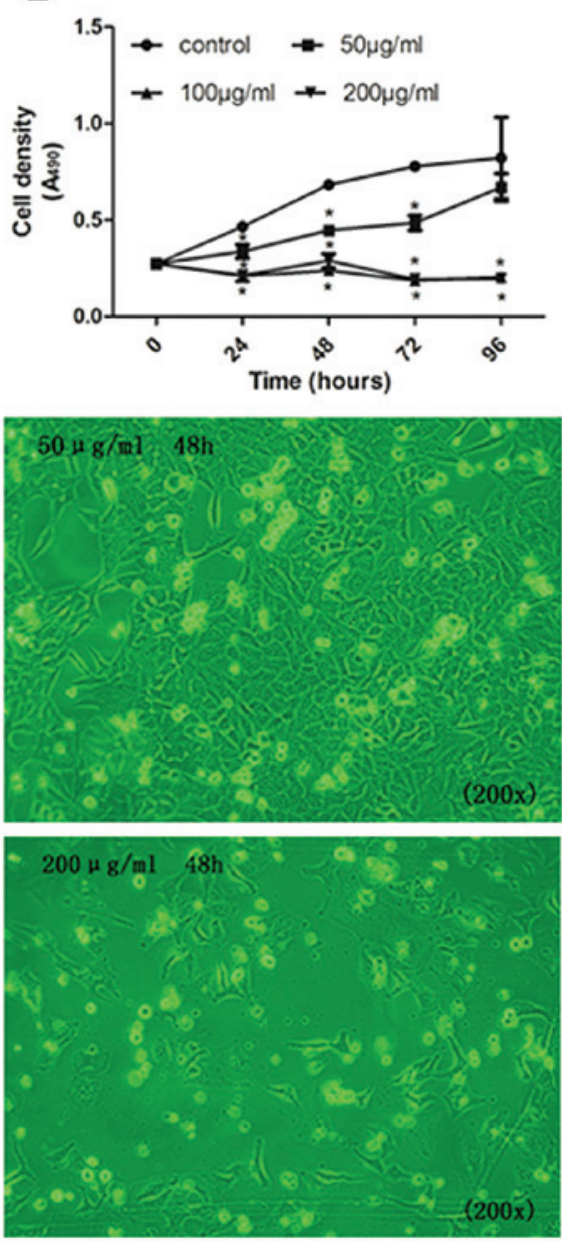

Figure 3. Effects of different concentrations of tea catechins on the cell growth of (A) NCI-H446 and (B) MSTO-211H cells. "P<0.05 compared to the control. (C) Representative cell growth density of NCI-H446 cells treated with $0,50100,200 \mu \mathrm{g} / \mathrm{ml}$ tea catechin by inverted microscopy (magnification, x200).
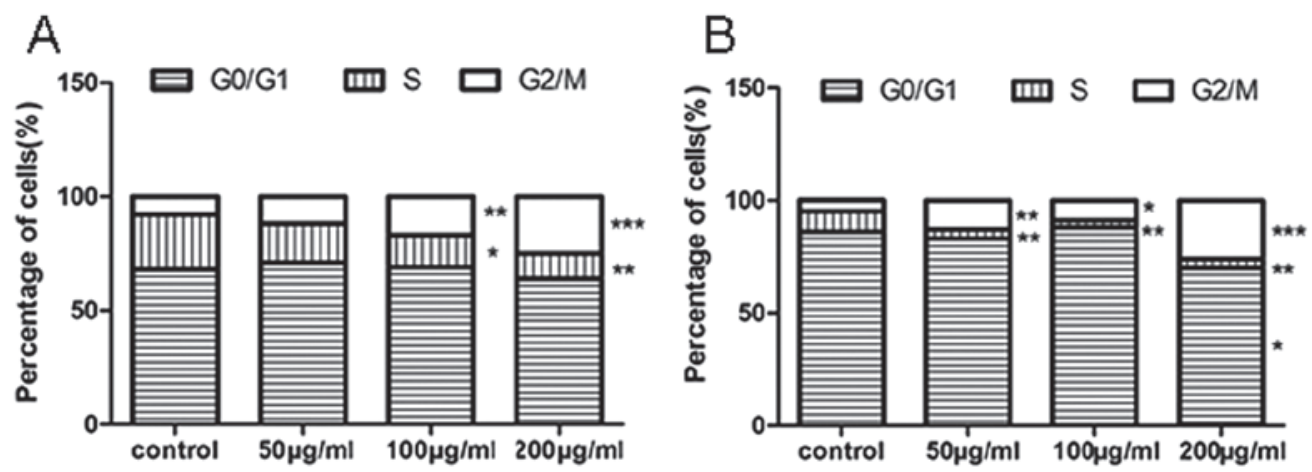

Figure 4. Treatment with tea catechins resulted in cell cycle arrest in (A) NCI-H446 and (B) MSTO-211H cells. ${ }^{*} \mathrm{P}<0.05,{ }^{* * *} \mathrm{P}<0.01$ and ${ }^{* * * *} \mathrm{P}<0.001$ compared to the control.

the LIN-28 expression at the protein level by western blot analysis and found that LIN-28 protein was decreased after tea catechin treatment (Fig. 2C and D). The results revealed that tea catechins not only affected the let-7 target $C-M Y C$ expression, but also repressed let-7 regulatory LIN-28 expression.

Tea catechins inhibit cell proliferation through a let-7 signaling pathway. To determine the cancer-preventive effect of the upregulation of let-7 by tea catechins on cell proliferation, we investigated the effect of tea catechins on cell growth and the cell cycle. The MTT results showed that tea catechins significantly suppressed NCI-H446 and MSTO-211H cell proliferation (Fig. 3). Additionally, the inhibitory effects were markedly exhibited in a dose- and time-dependent manner. At doses of 50,100 and $200 \mu \mathrm{g} / \mathrm{ml}$ of tea catechins, the percentages of inhibition were $28.9,43.13$ and $47.25 \%$ in NCI-H446 
cells, respectively (Fig. 3A) as well as $34.72,65.23$ and $57.69 \%$ in MSTO-211H cells, respectively (Fig. 3B). Furthermore, treatment of the cells with tea-catechin resulted in a significant dose-dependent decrease in cell density by suppression of NCI-H446 cell growth (Fig. 3C).

Tea catechins induce cell cycle arrest at the G2/M phase. We further investigated whether the upregulation of let-7 and the downregulation of the C-MYC/LIN-28 pathway by tea catechins affect the cell cycle. The DNA content analysis of the cell cycle was accomplished using flow cytometry. The results showed that the cell cycle was arrested at the $\mathrm{G} 2 / \mathrm{M}$ phase, and the number of cells in the S phase was significantly decreased at an appropriate dose of tea catechins in NCI-H446 and MSTO-211H lung cancer cells (Fig. 4A and B). These results indicate that treatment with tea catechins results in cell cycle arrest.

\section{Discussion}

The present study reveals that tea catechins significantly suppress cell growth by upregulating let-7 and downregulating the C-MYC/LIN-28 signaling pathway in lung cancer cells and mesothelioma cells which overexpress the C-MYC protooncogene. Tea catechins were found to exhibit inhibitory effects against the formation and development of various tumors. More specifically, tea catechins have been reported to alter the expression of C-MYC in lung carcinogenesis (29). Their anticancer effects include suppressing cell proliferation, promoting apoptosis, modulating signaling transduction and inhibiting cell invasion or metastasis (30). Interestingly, tea catechins also inhibit non-cancer (human embryonic lung fibroblast) cell proliferation (unpublished data from our own group), which indicates the suppression of cell growth is a non-specific effect. The in vitro cytotoxicity of tea catechins to cancer and normal cells has also been reported in previous studies $(31,32)$. Although the effects of tea catechins on inhibiting human cancer cell proliferation have been reported in several studies $(18,30)$, the precise mechanism of suppressing cancer cell growth is unclear. miRs are small non-coding RNA and are known to be important in the regulation of numerous cellular events (33). In particular, the let-7 miR family is an important class of cell regulatory factors of cellular growth. Our results also showed that let-7 is a tumor-suppressor miR and reduces C-MYC and LIN-28 expression in lung cancer cells. Recently, it has been shown that glia dedifferentiation and retinal regeneration are regulated through a LIN-28-dependent, let-7 miR signaling pathway (34). Moreover, the previous study indicates that LIN-28 functions as a negative regulator of let-7 miRs, and C-MYC suppresses mature let-7 miR expression through promotion of LIN-28 expression (15). Based on these studies, since C-MYC and LIN-28 regulate let-7 expression in cell differentiation and regeneration, here we confirmed our hypothesis that tea catechins suppress lung cancer cell growth via upregulation of let-7; through the inhibition of C-MYC and LIN-28 expression.

Recent studies have demonstrated that natural agents, such as B-DIM, isoflavone, genistein and curcumin, can alter the expression of specific miRs and thereby inhibit tumor growth (35-37). In addition, Zhang et al (38) reported that curcumin downregulates miR-186 and therefore induces cell apoptosis in lung cancer cells. The main component of tea catechins, EGCG, was found to upregulate miR-16 and downregulate its targeted gene $B c l-2$ to induce apoptosis in human cancer cells (23). This previous study also demonstrated that EGCG modified the expression of various miRs in human hepatocellular carcinoma HepG2 cells. In particular, 13 miRs were upregulated and 48 miRs were downregulated. Among them, the upregulated miRs included let-7a, let-7b and let-7c (23). Izzotti et al $(27,28)$ found that exposure to cigarette smoke alters miR expression in the lungs of rats. Our study demonstrated that expression of the tumor suppressors let-7a/7g was upregulated after tea catechin treatment. The properties and functions of these miRs may contribute to the differential anticancer effects of tea catechins. These emerging studies suggest that various agents affect mechanisms through miRNA pathways, and these support our finding that tea catechins alter the expression of various miRs and their targets or expression of related genes.

In conclusion, our study revelaed that tea catechins modulate the expression of various miRs in lung cancer cells; expression of let-7a-1 and let-7g was upregulated. The expression levels of let-7 target C-MYC and regulatory protein LIN-28 were reduced after treatment with a high dose of tea catechins. Based on the fact that let-7 overexpression suppresses cancer cell proliferation and tea catechins prevent cancers, our results found that tea catechins suppress cell growth via increased expression of let-7 miR and decreased expression of the targets, C-MYC and LIN-28.

\section{Acknowledgements}

We are grateful to Mrs Qiong Liu and Mrs Yanping Le for their technical assistance in flow cytometry and microscopy. This study was supported by research grants from the Key Scientific Research Fund of Zhejiang Provincial Education Department (Z201119414), the Natural Science Foundation of Zhejiang Province (Y12C060009), the Natural Science Foundation of Ningbo (201201A6110009), Zhejiang Provincial Research Project (2012F81G2070010), the Scientific Innovation Team Project of Ningbo (2011B82014), the Scientific Research Foundation of Graduate School of Ningbo University (G11JA007) and the K.C. Wong Magna Fund at Ningbo University.

\section{References}

1. Siegel R, Ward E, Brawley O and Jemal A: Cancer statistics, 2011: the impact of eliminating socioeconomic and racial disparities on premature cancer deaths. CA Cancer J Clin 61: 212-236, 2011

2. Rodriguez E and Lilenbaum RC: Small cell lung cancer: past, present, and future. Curr Oncol Rep 12: 327-334, 2010.

3. Osada $\mathrm{H}$ and Takahashi T: let-7 and miR-17-92: small-sized major players in lung cancer development. Cancer Sci 102: 9-17, 2011.

4. Bandi N, Zbinden S, Gugger M, et al: miR-15a and miR-16 are implicated in cell cycle regulation in a Rb-dependent manner and are frequently deleted or down-regulated in non-small cell lung cancer. Cancer Res 69: 5553-5559, 2009.

5. Wang QZ, Xu W, Habib N and Xu R: Potential uses of microRNA in lung cancer diagnosis, prognosis, and therapy. Curr Cancer Drug Targets 9: 572-594, 2009.

6. Cimmino A, Calin GA, Fabbri M, et al: miR-15 and miR-16 induce apoptosis by targeting BCL2. Proc Natl Acad Sci USA 102: 13944-13949, 2005.

7. Valeri N, Gasparini P, Fabbri M, et al: Modulation of mismatch repair and genomic stability by miR-155. Proc Natl Acad Sci USA 107: 6982-6987, 2010. 
8. Liu X, Sempere LF, Ouyang H, et al: MicroRNA-31 functions as an oncogenic microRNA in mouse and human lung cancer cells by repressing specific tumor suppressors. J Clin Invest 120 $1298-1309,2010$

9. Zhu S, Wu H, Wu F, Nie D, Sheng S and Mo YY: MicroRNA-21 targets tumor suppressor genes in invasion and metastasis. Cell Res 18: 350-359, 2008.

10. Johnson CD, Esquela-Kerscher A, Stefani G, et al: The let-7 microRNA represses cell proliferation pathways in human cells Cancer Res 67: 7713-7722, 2007.

11. Johnson SM, Grosshans H, Shingara J, et al: RAS is regulated by the let-7 microRNA family. Cell 120: 635-647, 2005.

12. He XY, Chen JX, Zhang Z, Li CL, Peng QL and Peng HM: The let-7a microRNA protects from growth of lung carcinoma by suppression of k-Ras and c-Myc in nude mice. J Cancer Res Clin Oncol 136: 1023-1028, 2010.

13. Wong TS, Man OY, Tsang CM, et al: MicroRNA let-7 suppresses nasopharyngeal carcinoma cell proliferation through downregulating c-Myc expression. J Cancer Res Clin Oncol 137: 415-422, 2011.

14. Lan FF, Wang H, Chen YC, et al: Hsa-let-7g inhibits proliferation of hepatocellular carcinoma cells by downregulation of c-Myc and upregulation of p16(INK4A). Int J Cancer 128: 319-331, 2011.

15. Dangi-Garimella S, Yun J, Eves EM, et al: Raf kinase inhibitory protein suppresses a metastasis signalling cascade involving LIN28 and let-7. EMBO J 28: 347-358, 2009.

16. Balentine DA, Wiseman SA and Bouwens LC: The chemistry of tea flavonoids. Crit Rev Food Sci Nutr 37: 693-704, 1997.

17. Dube A, Nicolazzo JA and Larson I: Chitosan nanoparticles enhance the intestinal absorption of the green tea catechins (+)-catechin and (-)-epigallocatechin gallate. Eur J Pharm Sci 41 : 219-225, 2010

18. Higdon JV and Frei B: Tea catechins and polyphenols: health effects, metabolism, and antioxidant functions. Crit Rev Food Sci Nutr 43: 89-143, 2003

19. Fujiki H, Yoshizawa S, Horiuchi T, et al: Anticarcinogenic effects of (-)-epigallocatechin gallate. Prev Med 21: 503-509, 1992.

20. Liao S, Umekita Y, Guo J, Kokontis JM and Hiipakka RA: Growth inhibition and regression of human prostate and breast tumors in athymic mice by tea epigallocatechin gallate. Cancer Lett 96: 239-243, 1995.

21. Hirose M, Mizoguchi Y, Yaono M, Tanaka H, Yamaguchi T and Shirai T: Effects of green tea catechins on the progression or late promotion stage of mammary gland carcinogenesis in female Sprague-Dawley rats pretreated with 7,12-dimethylbenz(a) anthracene. Cancer Lett 112: 141-147, 1997.

22. Fix LN, Shah M,Efferth T, Farwell MA and Zhang B: MicroRNA expression profile of MCF-7 human breast cancer cells and the effect of green tea polyphenon-60. Cancer Genomics Proteomics 7: 261-277, 2010

23. Tsang WP and Kwok TT: Epigallocatechin gallate up-regulation of miR-16 and induction of apoptosis in human cancer cells. J Nutr Biochem 21: 140-146, 2008.
24. Kumar MS, Erkeland SJ, Pester RE, Chen CY, Ebert MS, Sharp PA and Jacks T: Suppression of non-small cell lung tumor development by the let-7 microRNA family. Proc Natl Acad Sci USA 105: 3903-3908, 2008

25. Esquela-Kerscher A, Trang P, Wiggins JF, et al: The let-7 microRNA reduces tumor growth in mouse models of lung cancer. Cell Cycle 7: 759-764, 2008.

26. He X, Duan C, Chen J, Ou-Yang X, Zhang Z, Li C and Peng H: Let-7a elevates p21(WAF1) levels by targeting of NIRF and suppresses the growth of A549 lung cancer cells. FEBS Lett 583: 3501-3507, 2009.

27. Izzotti A, Calin GA, Arrigo P, Steele VE, Croce CM and De Flora S: Downregulation of microRNA expression in the lungs of rats exposed to cigarette smoke. FASEB J 23: 806-812, 2009.

28. Izzotti A, Calin GA, Steele VE, Cartiglia C, Longobardi M, Croce CM and De Flora S: Chemoprevention of cigarette smokeinduced alterations of microRNA expression in rat lungs. Cancer Prev Res (Phila) 3: 62-72, 2010.

29. Manna S, Mukherjee S, Roy A, Das S and Panda CK: Tea polyphenols can restrict benzo[a]pyrene-induced lung carcinogenesis by altered expression of p53-associated genes and H-ras, c-myc and cyclin D1. J Nutr Biochem 20: 337-349, 2009.

30. Yang CS and Wang X: Green tea and cancer prevention. Nutr Cancer 62: 931-937, 2010

31. Babich H, Krupka ME, Nissim HA and Zuckerbraun HL: Differential in vitro cytotoxicity of (-)-epicatechin gallate (ECG) to cancer and normal cells from the human oral cavity. Toxicol In Vitro 19: 231-242, 2005

32. Yang CS, Wang X, Lu G and Picinich SC: Cancer prevention by tea: animal studies, molecular mechanisms and human relevance. Nat Rev Cancer 9: 429-439, 2009.

33. Yang N, Coukos G and Zhang L: MicroRNA epigenetic alterations in human cancer: one step forward in diagnosis and treatment. Int J Cancer 122: 963-968, 2008.

34. Ramachandran R, Fausett BV and Goldman D: Asclla regulates Müller glia dedifferentiation and retinal regeneration through a Lin-28-dependent, let-7 microRNA signalling pathway. Nat Cell Biol 12: 1101-1107, 2010.

35. Li Y, VandenBoom TG II, Kong D, Wang Z, Ali S, Philip PA and Sarkar FH: Up-regulation of miR-200 and let-7 by natural agents leads to the reversal of epithelial-to-mesenchymal transition in gemcitabine-resistant pancreatic cancer cells. Cancer Res 69: 6704-6712, 2009

36. Sun Q, Cong R, Yan H, et al: Genistein inhibits growth of human uveal melanoma cells and affects microRNA-27a and target gene expression. Oncol Rep 22: 563-567, 2009.

37. Sun M, Estrov Z, Ji Y, Coombes KR, Harris DH and Kurzrock R: Curcumin (diferuloylmethane) alters the expression profiles of microRNAs in human pancreatic cancer cells. Mol Cancer Ther 7: 464-473, 2008.

38. Zhang J, Du Y, Wu C, et al: Curcumin promotes apoptosis in human lung adenocarcinoma cells through miR-186* signaling pathway. Oncol Rep 24: 1217-1223, 2010. 